\title{
CREEP LIFE ESTIMATION OF SERVICE EXPOSED ALLOY 625 AMMONIA CRACKER TUBES
}

\author{
M.D.Mathew ${ }^{1}$, K.Bhanu Sankara Rao ${ }^{1}$, S.L.Mannan ${ }^{1}$, K.Paknikar ${ }^{2}$ and \\ Raghubir Singh ${ }^{3}$ \\ ${ }^{1}$ Indira Gandhi Centre for Atomic Research, Kalpakkam - 603 102, India \\ ${ }^{2}$ Heavy Water Board, Bombay - 400 094, India \\ ${ }^{3}$ National Metallurgical Laboratory, Jamshedpur - 831 007, India
}

\begin{abstract}
Creep properties of service exposed ammonia cracker tubes of Alloy 625 have been studied after a re-solution annealing treatment at $1433 \mathrm{~K}$ for one hour. The tubes were retrieved after 60,000 hours of operation at $993 \mathrm{~K}$ and gas pressure of $14 \mathrm{MPa}$. Creep properties of the re-solution annealed material were evaluated to assess the suitability of these tubes for reuse as cracker tubes. Estimation of rupture life has been carried out using iso-stress and Larson-Miller parameter methods. Creep rupture strength and rupture ductility recovered substantially on re-solution annealing. Metallographic studies showed extensive precipitation of delta phase at test temperatures below $1023 \mathrm{~K}$.
\end{abstract}




\section{Introduction}

Alloy 625 is a solid solution strengthened nickel base superalloy containing substantial amounts of chromium (20-23 wt\%), molybdenum (8-10 wt\%), iron (5 wt\% max.) and niobium (3.15-4.15 $\mathrm{wt} \%$ ). The aluminium and titanium additions are properly adjusted for refining purposes and are intentionally kept low compared to alloys like Alloy 718 . In view of its excellent resistance to severely corrosive environments and good high temperature mechanical properties, this alloy was chosen for ammonia cracker tubes in heavy water plants where ammonia is cracked into nitrogen and hydrogen. During normal service, the cracker tubes are exposed to a temperature of about 993 $\mathrm{K}$ and gas pressure of $14 \mathrm{MPa}$. At these conditions, the tubes undergo creep deformation. Although the design life of the tubes was 100,000 hours, some failures have taken place after about 60,000 hours of service necessitating premature replacement of the cracker tubes. Since replacement of all the tubes is very expensive, studies have been underway to extend the life of the service exposed tubes through a rejuvenation heat treatment. A re-solution annealing treatment at $1433 \mathrm{~K}$ for one hour has been found beneficial with respect to tensile properties. The yield strength of the material declined from $927 \mathrm{MPa}$ after service to $470 \mathrm{MPa}$ on re-solution annealing compared to $352 \mathrm{MPa}$ for virgin material. The tensile elongation increased from $6 \%$ after service to $55 \%$ after re-solution treatment compared to $53 \%$ recorded for virgin material. In this paper, the creep properties of the resolution annealed tubes evaluated by isostress method and Larson-Miller Parameteric method are presented. The creep behaviour of re-solution annealed tubes has been rationalised on the basis of the microstructural changes. The remanent creep life of rejuvenated tubes has been assessed.

\section{Experimental}

The present investigation has been carried out using one of the cracker tubes which failed after 60,000 hours of service. The tube had a length of $13.5 \mathrm{~m}$ with an outside diameter of $88.9 \mathrm{~mm}$ and wall thickness of $7.95 \mathrm{~mm}$. Rectangular specimens of $25 \mathrm{~mm}$ gauge length, $7 \mathrm{~mm}$ width and $4 \mathrm{~mm}$ thickness were machined from the tube midwall in the longitudinal direction. Two series of creep rupture tests (named series I and series II) were conducted for determining the residual creep life. The series I tests were isostress tests conducted at six different temperatures between 1023 and $1148 \mathrm{~K}$ at intervals of $25 \mathrm{~K}$. In all these tests, the test temperatures were higher than the design temperature of $993 \mathrm{~K}$. The stress level was kept constant at $105 \mathrm{MPa}$. The second series of creep rupture tests (series II) are conducted in a broad range of temperatures (923 to $1023 \mathrm{~K}$ ) and stresses (100 to $600 \mathrm{MPa}$ ).

\section{$\underline{\text { Results and Discussion }}$}

\section{Rupture Life}

Among the various methods followed for estimating residual creep life of service exposed components, isostress creep testing is considered to provide realistic estimates of the remanent 
creep life[1]. This method involves conducting a batch of creep tests at temperatures greater than the service temperature and stress close to the service stress, and then extrapolating the rupture life-temperature data to the service temperature.

The isostress creep data al a stress level of $105 \mathrm{MPa}$ obtained in this study is plotted in Fig.1. The value of $105 \mathrm{MPa}$ has been arrived at after taking into account the hoop stress at the operating pressure of $14 \mathrm{MPa}$ and the factor of safety assumed in the design. Rupture life increased linearly with decrease in temperature (on semilog plot) in the range of 1073 to $1148 \mathrm{~K}$. Below $1073 \mathrm{~K}$, the slope of the line changed very drastically and the life obtained at lower temperatures was much lower than that would be expected by extrapolation from the higher temperature region. This is in contrast to the behaviour generally exhibited by engineering materials which display a change in slope due to detrimental changes in the microstructure at high temperatures. Graphical extrapolation of the low temperature region of the trend line predicted a residual life of about 55000 hours at the service temperature of $993 \mathrm{~K}$. Extrapolation based on the data for the temperature range 1073-1148 K predicted a residual life in excess of 200000 hours.

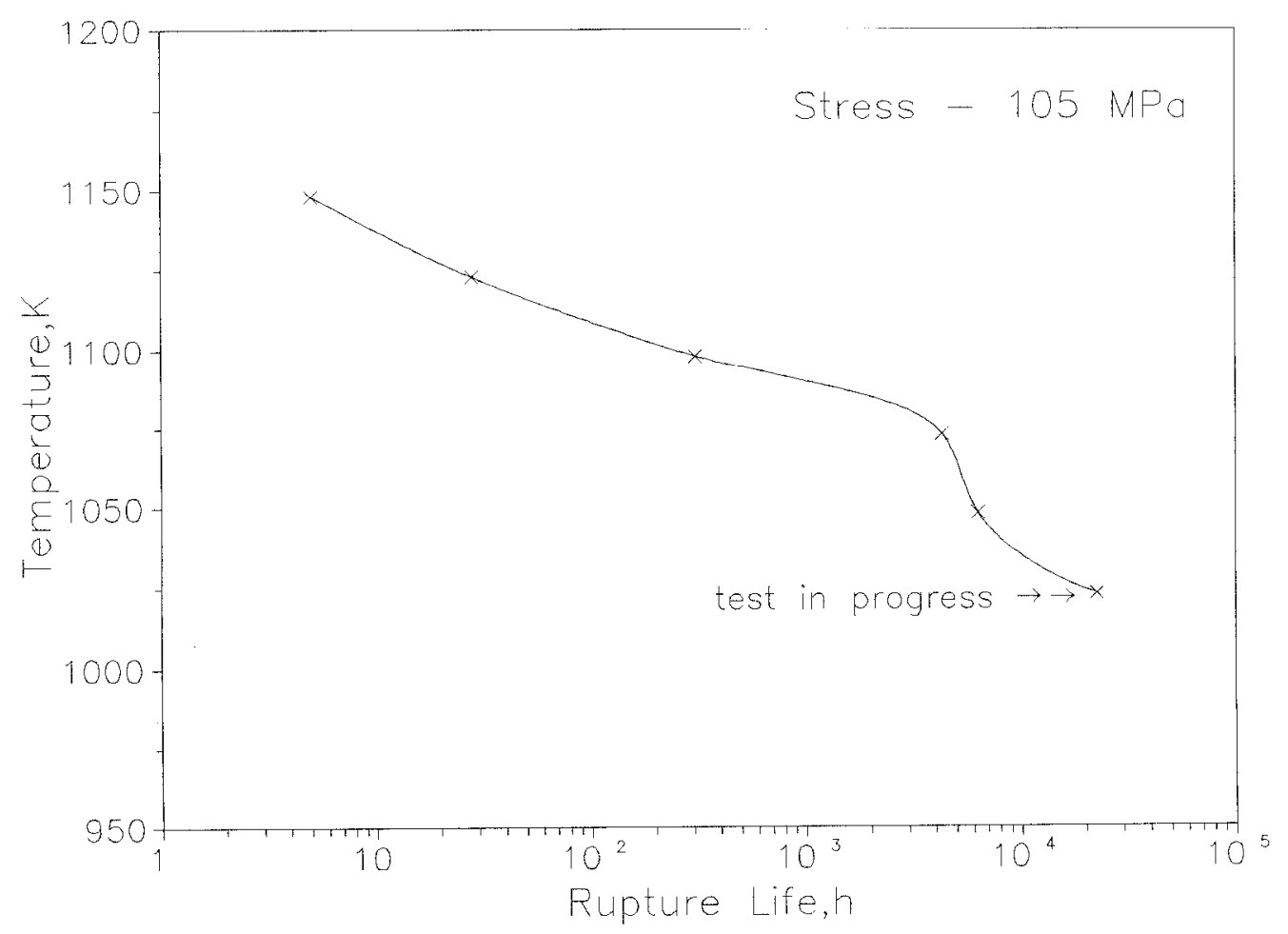

Fig.1. Variation of rupture life with temperature at $105 \mathrm{MPa}$ (Isostress plot).

A Larson-Miller Parameter (LMP) analysis has been made of the combined rupture life data obtained from series I and II tests. Figure 2 shows the variation of LMP with stress (semi log plot). A value of 20.7 has been uscd for the constant $C$ in the LMP equation, $L M P=T\left[C+\operatorname{logt}_{r}\right]$ where $t_{T}$ is the rupture life and $T$ is the temperature in $\mathrm{K}$. In the absence of reliable value for the constant $\mathrm{C}$, a value of $\mathrm{C}=20$ has been suggested for fitting the data[8]. The supplier of the tubes, 
however, had used a value of 20.7 for extrapolation in their test report and so the same value has been chosen for the present analysis. A good statistical fit has been obtained with a correlation coefficient of $R=0.97$. Using Fig. 2 , a rupture life of 58000 hours has been predicted at $993 \mathrm{~K}$ at a stress of $105 \mathrm{MPa}$. This value compares favourably with the predicted value of 55000 hours from isostress experiments. Surprisingly, the predicted values of rupture life of material after service followed by this heat treatment are close to the failure time of 60000 hours of virgin material in service.

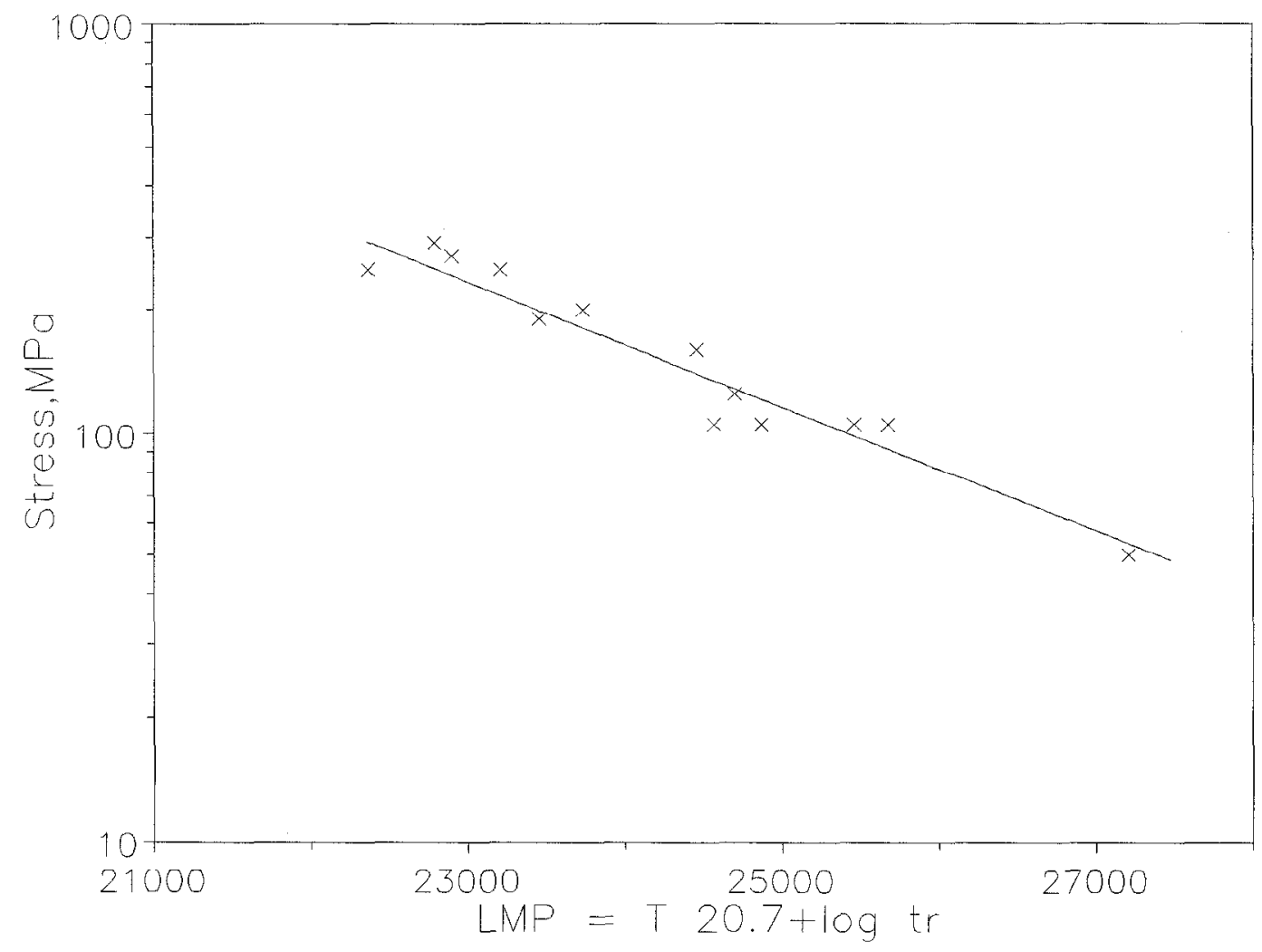

Fig.2. Larson-Miller Parameter plot of rupture data between $923 \mathrm{~K}$ and $1173 \mathrm{~K}$.

\section{Rupture Ductility}

Figure 3 shows the variation of rupture elongation with temperature at a constant stress of 105 MPa. The material showed very good ductility at higher temperatures. But with a decrease in temperature, rupture ductility decreased drastically from a high of $70 \%$ at $1148 \mathrm{~K}$ to less than $20 \%$ at about $1098 \mathrm{~K}$. Below $1098 \mathrm{~K}$, ductility did not show any appreciable change with temperature. Analysis of the entire ductility data showed that at test temperatures of $1023 \mathrm{~K}$ and below, the ductility is generally around $20 \%$ and that it does not vary with stress or temperature. At temperatures above $1023 \mathrm{~K}$, the ductility is high (40-65\%) and that it decreases with increasing rupture life irrespective of the test temperature [Fig.4]. 


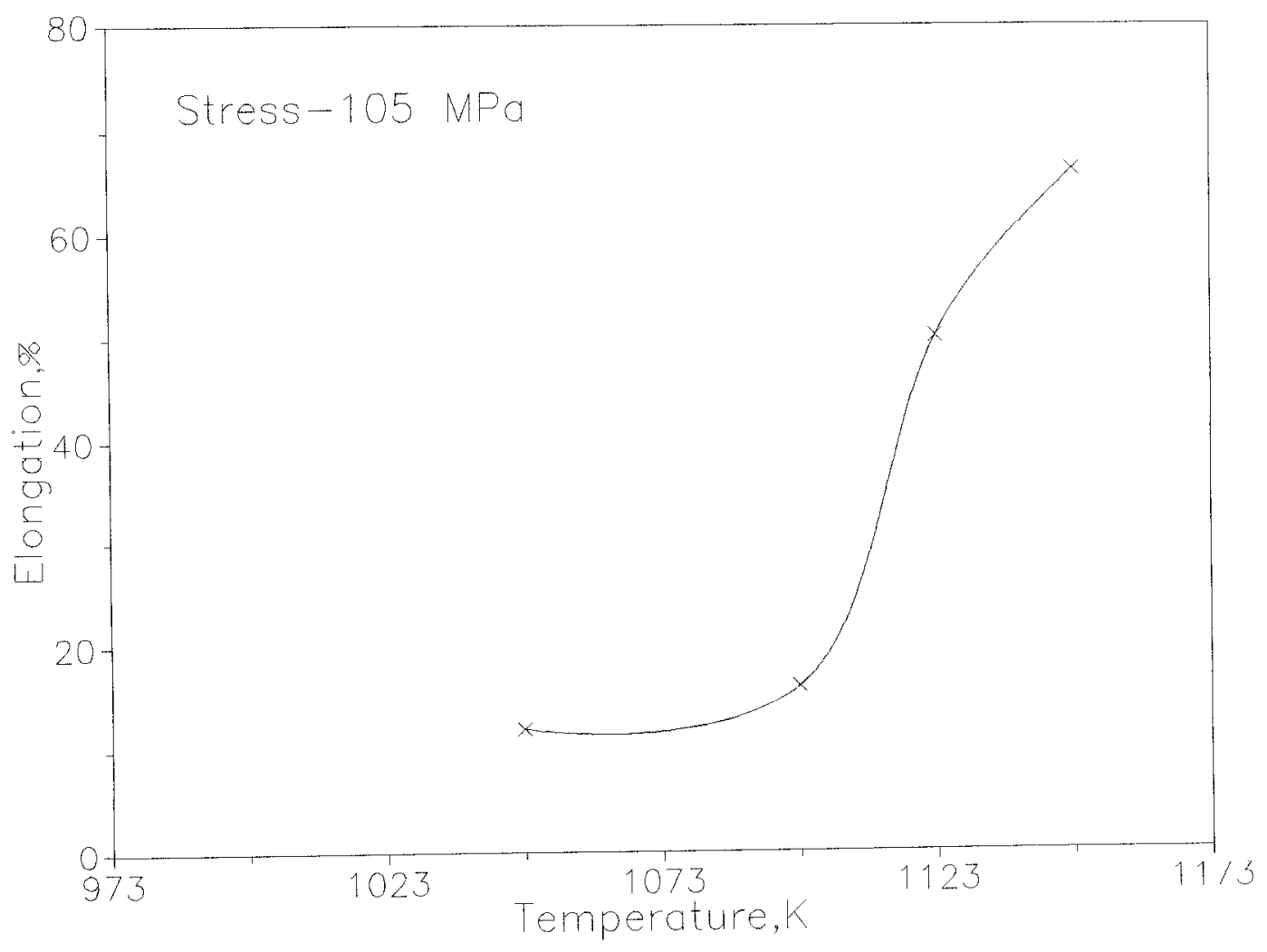

Fig.3. Variation of rupture elongation with temperature at $105 \mathrm{MPa}$.

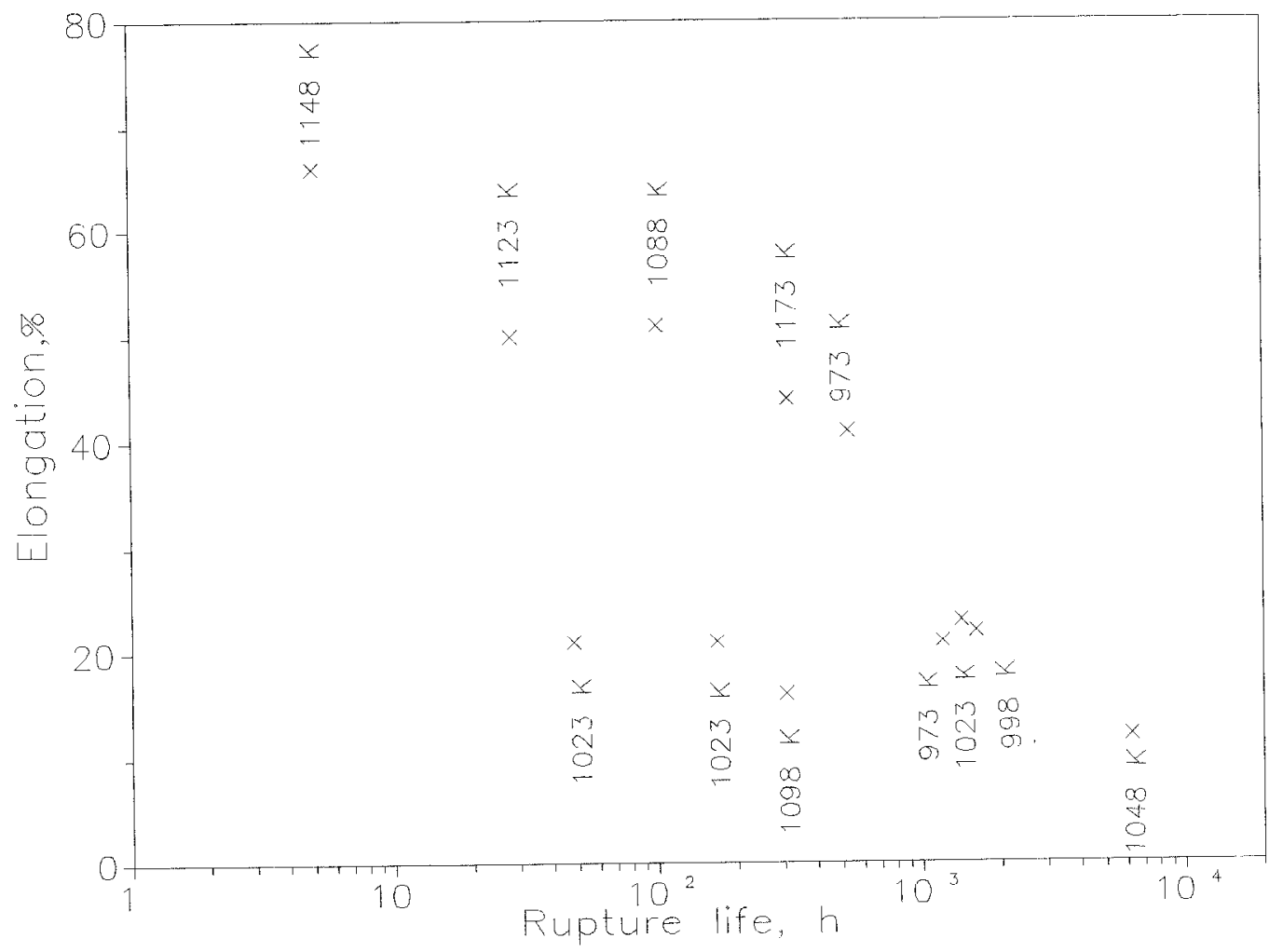

Fig. 4. Variation of rupture elongation with rupture life in the temperature range $973-1173 \mathrm{~K}$. 809 


\section{Precipitation and Damage Behaviour}

Detailed metallographic studies have been carried out on the creep damage and microstructural changes in the material. Wedge type of cracks have been generally observed at all the test conditions. Figure 5(a) shows typical creep damage observed at $1023 \mathrm{~K}$ with a rupture life of 170 hours, and the fracture surface of the specimen is shown in Fig. 5(b). Fracture appears to have taken place due to growth and linkage of cracks leading to plastic instability of the ligament between the intergranular cracks. Atthough Alloy 625 was originally developed as a solid solution
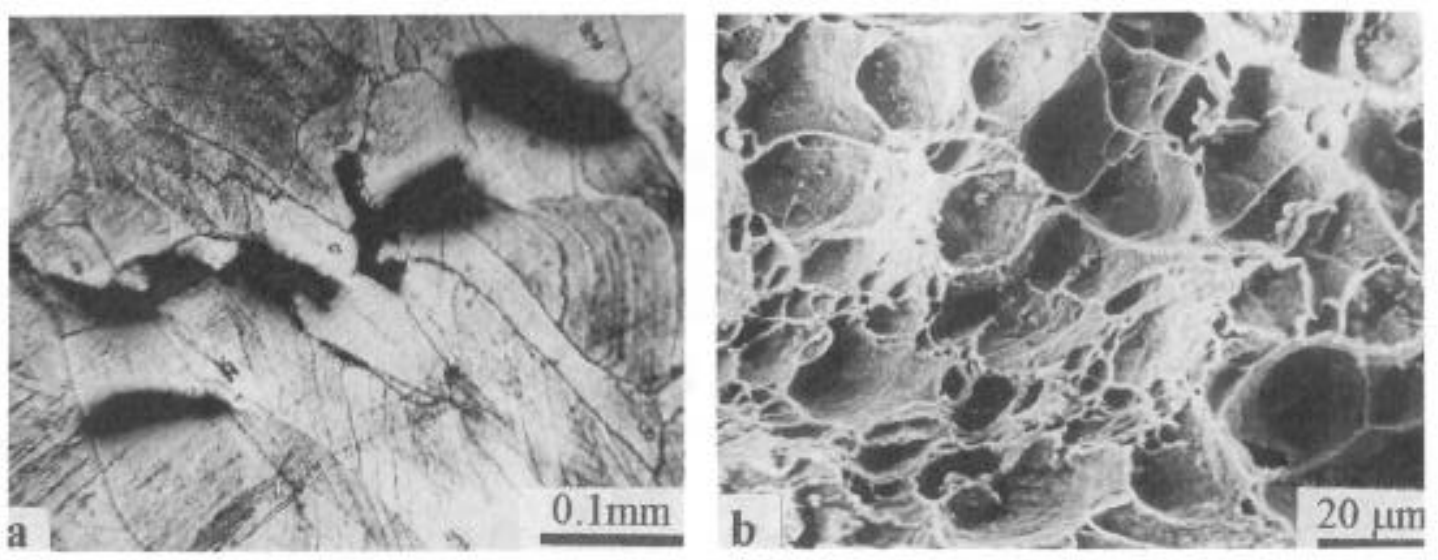

Fig.5. (a) Typical creep damage and (b) fracture surface of specimen tested at $1023 \mathrm{~K} ; \mathrm{t}_{\mathrm{r}}-170 \mathrm{~h}$.

strengthened alloy, several studies have shown that the material is microstructurally unstable on elevated temperature exposure [2-7]. It has been reported that types $\mathrm{MC}, \mathrm{M}_{6} \mathrm{C}, \mathrm{M}_{23} \mathrm{C}_{6}$ carbides and intermetallic phases $\left(\gamma^{\prime \prime}\right.$ and $\delta$ ) precipitate in this alloy depending upon the temperature and duration of ageing. Gamma double prime, which is a metastable phase with an ordered body centred tetragonal crystal structure of $\mathrm{Ni}_{3}(\mathrm{Nb}, \mathrm{Ti}, \mathrm{Al})$ composition was noticed to precipitate in the temperature range $923 \mathrm{~K}$ to $1023 \mathrm{~K}$. At temperatures higher than $1023 \mathrm{~K}$, $\delta$ phase (a stable orthorhombic phase) with composition $\mathrm{Ni}_{3}(\mathrm{Nb})$ is generally observed [7].

The microstructural changes in the creep tested specimens have been studied using Scanning Electron Microscope. The samples were given electrolytic etching using chromic acid to reveal the intermetallic phases. Below $1023 \mathrm{~K}$, there was no evidence of any matrix precipitation and only grain boundary precipitates were observed. At temperatures above $1023 \mathrm{~K}$, profuse precipitation of $\delta$ phase, as identified by its acicular morphology, has been observed in the intragranular regions. Figure $6(\mathrm{a})$ shows $\delta$ phase needles within the grains and carbides along the boundaries after creep testing at $1098 \mathrm{~K}$ for 300 hours. As the test temperature increases, the size of the needles increased and their number density decreased. These morphological changes are clearly evident from Fig.6(b) to 6(f) which shows the microstructural changes due to ageing of the material for 500 hours at $873,973,1023,1123$ and $1173 \mathrm{~K}$ respectively. There was no evidence of matrix precipitation upto $973 \mathrm{~K}$ whereas needle shaped $\delta$ phase particles were abundantly present at higher temperatures. 

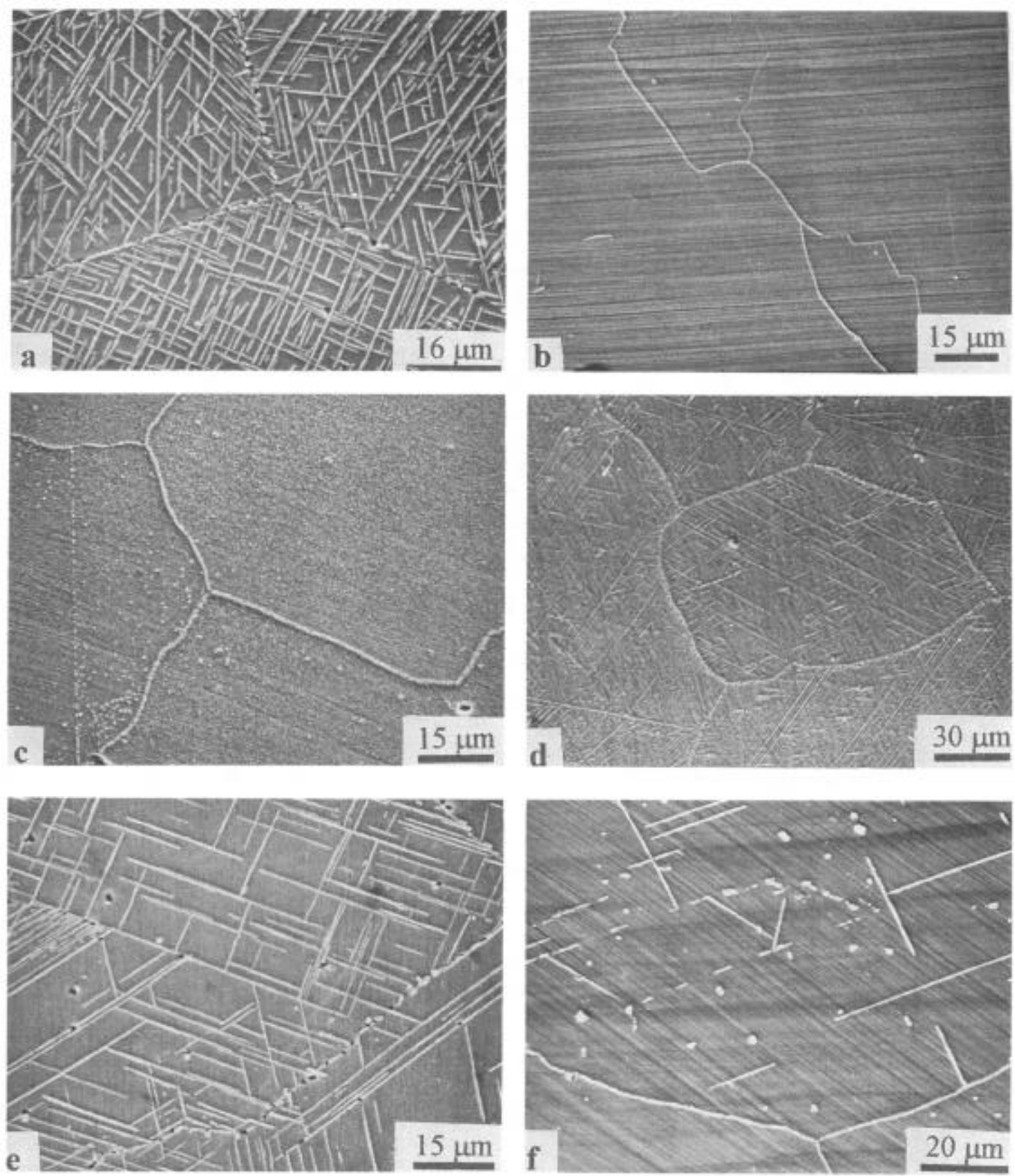

Fig.6. (a) Needle shaped delta-phase precipitates in specimen creep tested at $1098 \mathrm{~K} ; \mathrm{t}_{\mathrm{r}}-300 \mathrm{~h}$. Microstructure after ageing for 500 hours at (b) $873 \mathrm{~K}$, (c) $973 \mathrm{~K}$, (d) $1023 \mathrm{~K}$, (e) $1123 \mathrm{~K}$ and (f) $1173 \mathrm{~K}$. 
From the precipitation behaviour of the material observed in the present study, it is concluded that the two slope behaviour of the isostress curve (Fig.1) is due to the precipitation of intermetallic phases. The microstructural evidence suggests that the greater sensitivity of rupture life with temperature below $1073 \mathrm{~K}$ arises due to the precipitation of $\gamma^{\prime \prime}$ phase. Although TEM studies have not been carried out, it is known from the literature that peak hardness of this material occurs when aged at $973 \mathrm{~K}$ due to precipitation of $\gamma^{\prime \prime}$ phase[5,6]. It is suggested that the strengthening effect of $\gamma^{\prime \prime}$ phase is also responsible for the lower ductility observed in below $1023 \mathrm{~K}$ (Figs. 2 and 3 ). Precipitation and growth of $\delta$ phase leads to loss of solid solution strengthening and order strengthening from $\gamma^{\prime \prime}$, and results in recovery of ductility.

\section{Conclusions}

1. Resolution annealing treatment was found to be beneficial to restore the creep rupture strength of service exposed Alloy 625 tubes.

2. Both isostress and LMP approaches predicted the same value of rupture life.

3. Rupture ductility was low at temperatures below $1023 \mathrm{~K}$.

4. Precipitation of $\delta$ phase which took place at $1023 \mathrm{~K}$ and above had no detrimental effect on creep rupture ductility.

\section{References}

1. R. Viswanathan, Damage Mechanisms and Life Assessment of High Temperature Components (1990), p.59.

2. J.W. Brooks and P.J. Bridges, Superalloys 1988, S.Reichman, D.N. Dubil, G. Maurer, S. Antolovich and C Lund (eds.), The Metallurgical Society (1988) p.33.

3. L. Ferrer, B.Pieraggi and J.F.Uginet, Superalloys 718, 625 and Various Derivatives, Edward E Loria (ed.), The Minerals, Metals and Materials Society (1991) p.217.

4. M.Kohler, ibid,p.363.

5. R.Cozar, M.Rouby, B.Mayonobe and C.Morizot, ibid, p.423.

6. Chantal Vernot-Loirer and Francosis Cortial, ibid, p.409.

7. John F Radavich and Andrea Fort, ibid, p.635.

8. Ulrich Heubner and Michael Kohler, Superalloys 718, 625 and Various Derivatives, Edward E Loria (ed.), The Minerals, Metals and Materials Society (1994) p.479. 